$45 \mid 2010$

Langue française, identité(s) et école(s) : le cas de la minorité catholique au Levant (milieu XIX ${ }^{\mathrm{e}}-\mathrm{XX}^{\mathrm{e}}$

siècles). Représentations identitaires et apprentissage des langues : Europe, bassin méditerranéen ( $\left.\mathrm{XV}\right|^{\mathrm{e}}-\mathrm{XX}{ }^{\mathrm{e}}$ siècles)

\title{
Présentation
}

\section{Karène Sanchez-Summerer}

\section{(2) OpenEdition}

Édition électronique

URL : https://journals.openedition.org/dhfles/2400

DOl : $10.4000 /$ dhfles. 2400

ISSN : 2221-4038

Éditeur

Société Internationale pour l'Histoire du Français Langue Étrangère ou Seconde

Édition imprimée

Date de publication : 1 juin 2010

Pagination : 7-8

ISSN : 0992-7654

\section{Référence électronique}

Karène Sanchez-Summerer, "Présentation », Documents pour l'histoire du français langue étrangère ou seconde [En ligne], 45 | 2010, mis en ligne le 28 août 2013, consulté le 27 mai 2021. URL : http:// journals.openedition.org/dhfles/2400 ; DOI : https://doi.org/10.4000/dhfles.2400

Ce document a été généré automatiquement le 27 mai 2021.

(c) SIHFLES 


\title{
Présentation
}

\author{
Karène Sanchez-Summerer
}

1 Sous le titre « Langue(s), identité(s) et écoles : le cas de la minorité catholique au Levant (milieu du XIX ${ }^{e}-X^{e}$ siècles) », le présent volume publie en première partie deux des communications présentées lors de la journée d'étude tenue à Leyde le 11 décembre 2009, l'une consacrée aux minorités catholiques de Palestine et la place de la langue française dans cette partie du Moyen-Orient (K. Sanchez-Summerer), l'autre portant sur les catholiques libanais et leurs écoles dans la première moitié $\mathrm{du} \mathrm{XX}^{\mathrm{e}}$ siècle (E. Möller). Ces deux textes montrent la place, le rôle, l'importance du français pour ces communautés, dans ce qu'on appelait le Levant, le terme étant ici employé dans le sens qu'il avait durant l'entre-deux-guerres, c'est-à-dire synonyme d'Orient, compre-nant aussi bien les franges maritimes que leurs arrière-pays respectifs. Nous avons joint à ces deux contributions un texte de D. Omer qui analyse la place qui fut accordée par l'Alliance israélite universelle, au-delà du français, aux différentes langues parlées dans l'environnement : leur importance relative, la nécessité de les enseigner, les tentatives pour y parvenir, certaines réticences à leur égard.

2 La journée d'étude s'était ouverte par une communication de W. Frijhoff, qui sous la forme d'un cas d'école, montrait avec l'exemple des Pays-Bas, la relation, complexe, évolutive, géographiquement variable sur un même territoire, entre langue(s) et religion(s). L'auteur y souli-gnait notamment le rôle de la différenciation linguistique dans le pro-cessus de formation identitaire confessionnelle et le rôle temporaire du français en tant qu'allié linguistique parmi la minorité catholique.

Historien du religieux, spécialiste des chrétiens d'Orient et des missions chrétiennes en Orient, B. Heyberger a préfacé ce premier ensemble.

4 Un deuxième volet est consacré aux « Représentations identitaires et à l'apprentissage des langues,en Europe et dans le bassin méditerranéen, du XVI ${ }^{\mathrm{e}}$ au XX siècle ». Cette partie reprend deux des présentations faites sous forme d'affiches lors de la journée d'étude de Leyde, l'une consacrée aux Pays-Bas, par M. van Strien-Chardonneau et M-C. Kok Escalle, l'autre portant sur l'Italie, traitée par N. Minerva. L'une et l'autre abordent la question de la place du français dans la construction de l'identité nationale de leurs pays respec-tifs. Nous avons joint à ces deux présentations le texte d'une communi- 
cation faite par J. Nordblad lors de la journée d'étude de la SIHFLES, «Accueil des jeunes chercheurs " (INALCO, Paris, 20 juin 2009). J. Nordblad analyse deux exemples parallèles d'imposition de la langue nationale à des groupes minoritaires parlant une langue régionale, d'un côté en Bretagne avec le français, d'autre part en Tornédalie avec le suédois. Identités et école(s) ici se rencontrent de façon sinon conflictuelle, du moins radicale.

Dans son ouvrage Lingua franca, J. Dakhlia souligne que «l'adéquation langue/identité est loin d'être automatique, les communautés pouvant être plurilingues ou employer des variétés de langues mixtes, ce qui pose la question du rôle et de la fréquence du plurilinguisme ». Le XIIe congrès de la FIPF, en 2008, insistait, quant à lui, sur la construction de l'identité culturelle et ses racines dans l'environnement géographique, historique, social, politique, scolaire et religieux, ainsi que sur les variations importantes selon que la personne vit en milieu linguistique majoritaire ou minoritaire, dans une culture multi-ethnique ou non. Durant une période qui correspond à la montée des impérialismes et des nationalismes en Europe et au Levant, les langues se chargent d'affect. Il y avait donc lieu de s'interroger sur les types de relations entre langue(s), identité(s) et écoles pour différentes minorités, et sur la manière dont le français est entré en jeu dans le processus de construction sociale de l'identité. Perçu longtemps comme une langue de prestige, mais aussi comme langue de commerce, d'éducation, d'appartenance religieuse, de protection pour les catholiques, le français a souvent changé de statut. Les intervenants de la journée d'étude organisée à Leyde, tout comme d'autres intervenants de la SIHFLES, se sont penchés sur ces relations entre langue(s) et identité au sein de différents systèmes scolaires et de divers groupes sociaux.

Ce numéro propose également une série de comptes rendus de lecture. Nombreux sont en effet les ouvrages portant sur l'histoire de l'ensei-gnement et de la diffusion du français, langue étrangère, langue seconde, langue maternelle, qui ont ces derniers temps attiré notre attention.

\section{AUTEUR}

\section{KARÈNE SANCHEZ-SUMMERER}

Université de Leyde 